\title{
ESTUDO DA HIDRÓLISE ENZIMÁTICA DE BIOMASSA DE MICROALGA EMPREGANDO UMA SEQUÊNCIA DE ENZIMAS
}

\author{
JULICH, J.'; GASSEN, M. ${ }^{2}$; WERLANG, E. B. ${ }^{1}$; MÜLLER, M. V. G. ${ }^{2}$; SILVA, G. DE A. ${ }^{3}$; NEVES, F. DE F. ${ }^{4}$; \\ SCHNEIDER, R. C. S. ${ }^{5}$
}

PALAVRAS CHAVE: Sacarificação. Arthospira platensis. Hidrólise. Spirulina

\begin{abstract}
RESUMO
O emprego de microalgas para desenvolvimento de produtos está em pleno desenvolvimento considerando a composição de diversas espécies e a adaptação das mesmas ao meio de cultivo. Neste trabalho realizou-se o estudo da hidrólise enzimática da biomassa da microalga considerando a potencialidade de produção a partir de cepas de Chlorella sp., Scenedesmus sp., e Spirulina (Arthrospira platensis) empregando uma sequência de enzimas composta de duas amilases e dois complexos de celulases. Para tanto, foi realizado inicialmente a caracterização das espécies, seguindo-se o estudo com a Spirulina, que apresentou $40,02 \%$ de carboidratos e mais que a metade do teor em amido $(24,95 \%)$ se mostrando promissor o seu uso para a otimização da hidrólise enzimática. Os melhores resultados de conversão foram encontrados com 12 FPU da enzima CTec2 enquanto que foi com 6,9 FPU da enzima HTec2, alcançando próximo a $100 \%$ de rendimento. Desta forma pode-se concluir que a hidrólise empregando uma sequência de enzimas, $\square$-amilase, glucoamilase e celulases mostrou-se eficiente para a microalga Spirulina, mostrando a viabilidade de aplicação da biomassa para $o$ desenvolvimento de outros produtos, tornando a produção de matéria prima para etanol mais renovável.
\end{abstract}

\section{ENZYMATIC HYDROLYSIS STUDY OF MICROALGAE BIOMASS USING AN ENZYME SEQUENCE}

KEYWORDS: Saccharification. Arthospira platensis. Hydrolysis. Spirulina

\begin{abstract}
The products development using microalgae is being studied considering the composition of several species and their adaptation to the culture medium. In this work the microalgae enzymatic hydrolysis was studied from the strains of Chlorella sp., Scenedesmus sp., and Spirulina (Arthrospira platensis) using an enzyme sequence composed of two amylases and two complexes of cellulases. The characterization of those species was initially performed, followed by the Spirulina study, which presented $40.02 \%$ of carbohydrates and most of it was starch (24.95\%), showing a promise alternative for enzymatic hydrolysis. The optimal conversion corresponds to the enzyme CTec2 by adding $12 \mathrm{FPU}$, whereas for the enzyme HTec2 by adding 6.9 FPU, reaching close to $100 \%$ yield. From this study, the hydrolysis using a sequence of enzymes, $\square$-amylase, glucoamylase and cellulases proved to be efficient for Spirulina microalgae, showing the feasibility of biomass application for the development of alternative feedstock for a renewable ethanol production.
\end{abstract}

${ }^{1}$ Graduada em Química e acadêmica do curso de Engenharia Química da Universidade de Santa Cruz do Sul (UNISC).

${ }^{2}$ Acadêmica do curso de Engenharia Ambiental da Universidade de Santa Cruz do Sul (UNISC).

\footnotetext{
${ }^{1}$ Pós-graduanda em Tecnologia Ambiental da Universidade de Santa Cruz do Sul (UNISC).

${ }^{2}$ Docente do Departamento de Biologia e Farmácia na Universidade de Santa Cruz do Sul (UNISC).

${ }^{3}$ Acadêmica do curso de Engenharia de Pesca da Universidade do Estado de Santa Catarina (UDESC-Laguna).

${ }^{4}$ Docente do Departamento de Engenharia de Pesca e Ciências Biológicas na Universidade do Estado de Santa Catarina (UDESC-Laguna).

${ }^{5}$ Docente do Departamento de Química e Física na Universidade de Santa Cruz do Sul (UNISC).
} 


\section{INTRODUÇÃO}

Microalgas são microrganismos que podem crescer rapidamente e viver em condições adversas, adaptando-se facilmente as condições ambientais, devido a sua estrutura unicelular ou multicelular simples (Abomohra et al., 2016; Mata et al., 2010; Moreno-Garcia et al., 2017). Esta habilidade auxilia efetivamente na remediação de meios eutrofizados e na captura de $\mathrm{CO}_{2}$, não dependendo da disponibilidade de terras aráveis e liberando, via fotossíntese, $\mathrm{O}_{2}$ para a atmosfera (Chen et al., 2018; Demirbas, 2011; Hernández et al., 2015; Vo et al., 2018).

Associado aos ganhos ambientais diretos do cultivo de microalgas, há a potencialidade de aproveitamento da biomassa produzida para aplicação industrial. A biomassa de microalga é rica em lipídeos, proteínas, carboidratos e pigmentos, podendo ser utilizada em inúmeros processos para o desenvolvimento de bioprodutos, como biocombustíveis. Durante muitos anos a fração lipídica foi utilizada como fonte primária nas pesquisas para a produção de biodiesel. Nos últimos anos, as pesquisas também estão sendo voltadas para a conversão dos carboidratos em bioetanol, ácido láctico e biopolímeros, entre outros bioprodutos (Sivaramakrishnan \& Incharoensakdi, 2018). Conforme a avaliação bibliométrica da Figura 1 o bioetanol de microalgas é uma opção para a produção de biocombustíveis sendo estudado a partir de condições padrões, de biomassa produzida em meio efluente e, considerando a quantidade de carboidrato presente em cada espécie utilizada. Além disso, considera-se a importância da produção de etanol associado a produção de outros combustíveis, uma vez que é possível aproveitar os carboidratos após a extração de lipídeos, como pode ser observado na Figura 1 pela interação entre biodiesel e bioetanol.

Figura 1. Avaliação bibliométrica correlacionando "biofuel" e "microalgae" a partir da base Web of Science seguido de análise no software Voswiewer v. 1.6.11 (considerando palavras com no mínimo 16 coocorrências).

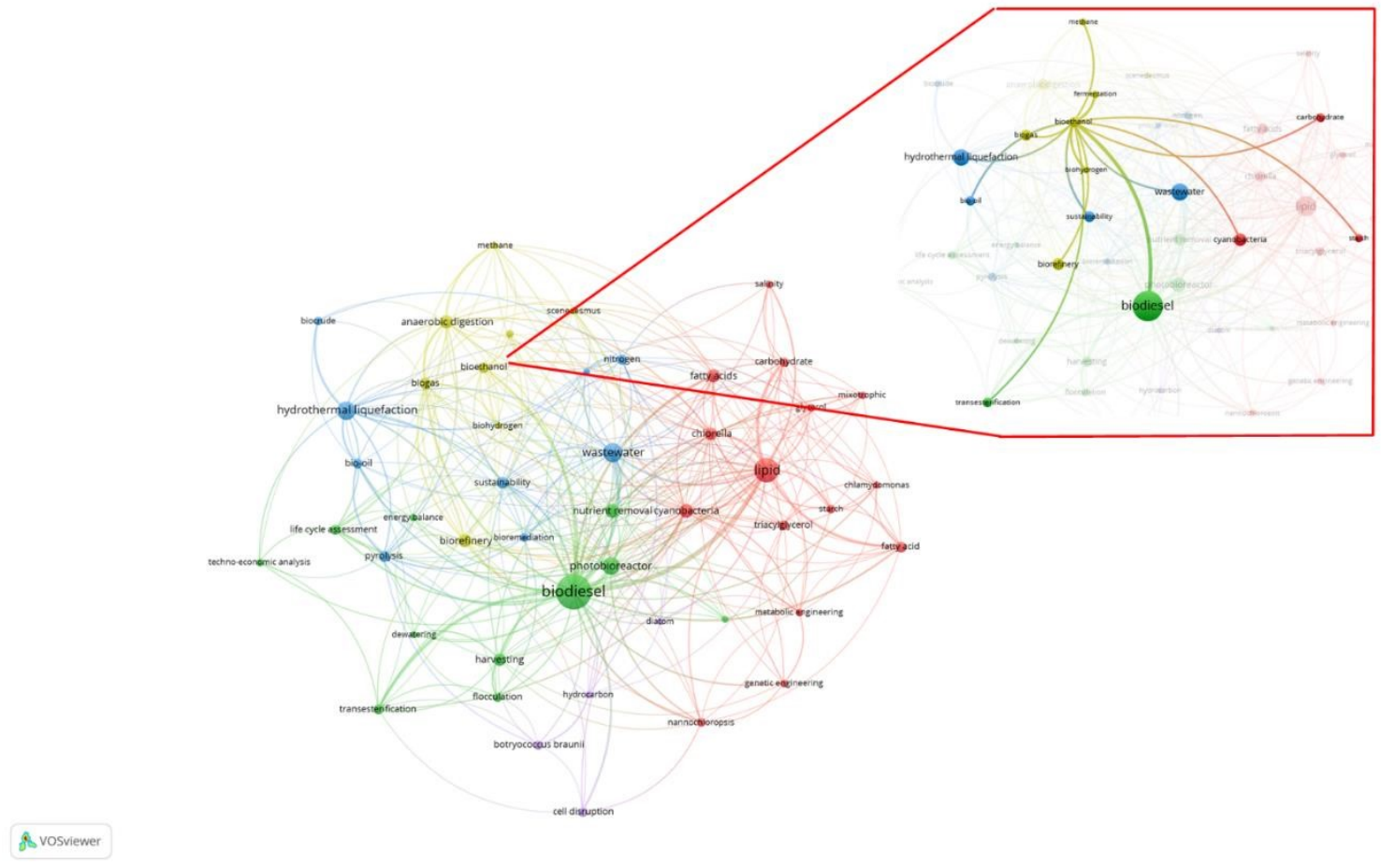

Inúmeras espécies de microalgas possuem potencialidade de uso devido ao seu elevado teor de 
carboidratos. Dentre os gêneros comumente estudados destacam-se Chlorella sp., Scenedesmus sp., e Spirulina sp. A parede celular da Spirulina, por exemplo, é composta predominantemente por polissacarídeos do tipo hexose, com baixos teores de pentoses, tornando-a muito promissora para a produção de bioetanol (Rempel et al., 2018).

A produção de bioetanol ocorre basicamente em três estágios: 1) recuperação da fração fermentável presente na célula na forma de amido e outros açúcares; 2) hidrólise dos açúcares utilizando diversos tratamentos, como enzimático e químico e; 3) fermentação dos açúcares utilizando microrganismos como leveduras e bactérias para a produção de bioetanol (Raheem et al., 2018).

A composição de carboidratos das microalgas é principalmente polissacarídeo que está nas paredes celulares e amido, sendo que seu percentual varia entre cepas, podendo atingir até $70 \%$ do peso seco. Além disso, a celulose é relatada como o principal componente estrutural da parede celular da maioria das espécies de microalgas (Harun \& Danquah, 2011). Para que estes polissacarídeos possam ser utilizados para a produção de etanol, é necessário a hidrólise dos mesmos, convertendo-os em monossacarídeos. A partir de biomassa de microalgas, a hidrólise pode ser química e/ou enzimática. Embora o método químico produza altas concentrações de açúcares fermentescíveis em um curto espaço de tempo, o mesmo requer condições severas de reação, liberando subprodutos, os quais podem inibir o processo de fermentação e levar a resultados dispendiosos de descarte de resíduos. Em contraste, a hidrólise enzimática também produz grandes quantidades de açúcares fermentescíveis, sob condições suaves e com maior tempo, sem produzir alta concentração de substâncias inibidoras (Al Abdallah et al., 2016; Hernández et al., 2015).

Desta forma, objetivou-se o estudo da hidrólise enzimática da biomassa da microalga considerando a potencialidade de produção a partir de cepas de Chlorella sp., Scenedesmus sp., e Spirulina (Arthrospira platensis) empregando uma sequência de enzimas composta de duas amilases e dois complexos de celulases.

\section{MATERIAIS E MÉTODOS}

\subsection{Caracterização da biomassa}

Foram utilizadas biomassas de cepas de Chlorella sp., Scenedesmus sp., e Spirulina (Arthrospira platensis) sendo que as duas primeiras foram provenientes de pesquisas com fotobiorreatores fechados do Centro de Excelência em Produtos e Processos Oleoquímicos e Biotecnológicos (CEPPOB) da Universidade de Santa Cruz do Sul (UNISC) e a última proveniente de produção em sistema aberto (Raceway ponds) do Laboratório de Cultivo e Biotecnologia de Algas (LCBA) da Universidade do Estado de Santa Catarina (UDESC-Laguna).

A composição elementar das microalgas foi determinada em um analisador elementar (CHNS) da Perkin Elmer PE-2400. Para a determinação do teor de proteínas, multiplicou-se o valor encontrado para o nitrogênio total pelo fator de correção de 4,78 de acordo com Templeton and Laurens (2015). O teor de cinzas foi realizado em mufla por $6 \mathrm{~h}$ a $575^{\circ} \mathrm{C}$ de acordo com a metodologia descrita pela NREL-USA (Dowe \& McMillan, 2008). A quantidade de lipídeos foi determinada através de uma adaptação do método de extração descrito por Bligh and Dyer (1959).

A determinação de carboidratos totais foi constituída de uma hidrólise ácida, em que as moléculas de polissacarídeos são convertidas à monossacarídeos. O método utilizado foi descrito pela National Renewable Energy Laboratory (NREL-USA) (Sluiter et al., 2008).

A determinação de amido foi realizada utilizando-se $\alpha$-amilase (Liquozyme Supra) e glucoamilase (AMG 300L), em banho-maria com agitação por 2 horas a $90^{\circ} \mathrm{C}$ e $60^{\circ} \mathrm{C}$ respectivamente. $\mathrm{O}$ sobrenadante foi centrifugado a $13.400 \mathrm{rpm}$ 
por 30 min e a fase líquida foi centrifugada e armazenada para análise por Cromatografia a Líquido de Alta Eficiência (HPLC) (Schneider et al., 2018). A análise cromatográfica para quantificação dos carboidratos foi através d a determinação de glicose com o cromatógrafo da marca Shimadzu, com detecção por índice de refração (RID), utilizando coluna RHM Monosaccharide $\mathrm{H}^{+}, 300 \mathrm{~mm}$ x 7,8 mm, com temperatura do forno de $85^{\circ} \mathrm{C}$, fase móvel foi composta por água ultrapura (Milli-Q), e eluição com vazão de fluxo $0,8 \mathrm{~mL} \mathrm{~min}^{-1}$ e o volume de injeção $20 \mu \mathrm{L}$.

\subsection{HIDRÓLISE ENZIMÁTICA}

Esta etapa foi realizada apenas com a biomassa de microalga que apresentou alto teor de carboidratos. Na sacarificação realiza-se a hidrólise enzimática da biomassa de microalga onde experimentos de concentração de enzima são realizados para verificar a melhor concentração necessária para a produção do hidrolisado com maior concentração em açúcares, conforme adaptação do método descrito por Fernandes et al. (2011).

Para a hidrólise enzimática, pesou-se, em frasco tipo Shott, $0,1 \mathrm{~g}$ de biomassa moída da microalga que passou pelo pré-tratamento com etanol, sob ultrassonicação, visando a retirada de pigmentos que pudessem interferir na análise dos produtos. Adicionou-se $20 \mathrm{~mL}$ de uma solução de $\alpha$-amilase (Liquozyme Supra), contendo 1,134 KNU de enzima. O pH foi ajustado a pH 6 com solução de ácido fosfórico $0,1 \%$. As amostras permaneceram em banho-maria a $90{ }^{\circ} \mathrm{C}$ por $2 \mathrm{~h}$, sendo homogeneizadas a cada $5 \mathrm{~min}$. Após esse período, adicionou-se $0,1 \mathrm{~mL}$ de solução da glucoamilase (AMG 300L), contendo $0,75 \mathrm{AGU}$, e os recipientes foram agitados a $200 \mathrm{rpm}$, durante $2 \mathrm{~h}$ e a $60{ }^{\circ} \mathrm{C}$.

Para a etapa seguinte foram empregadas as enzimas CTec2 e HTec2 da marca Novozyme com atividade enzimática de 168,2 FPU e 27,6 FPU, respectivamente, determinada pelo método descrito por Adney and Baker (2008).

No experimento, adicionaram-se volumes de $1 ; 0,75 ; 0,5 ; 0,375 ; 0,25$ e 0,125 mL da celulase (HTec2 e CTec2), gerando concentrações de 1,$7 ; 3,5 ; 5,2 ; 6,9 ; 10,35$ e 13,8 FPU para enzima HTec2 e concentrações de 2; 5; 8; $10 ; 20$ e 30 FPU para enzima CTec2, permanecendo sob agitação constante a $200 \mathrm{rpm}$, durante $72 \mathrm{~h}$ e a $50^{\circ} \mathrm{C}$. Ao final, as amostras foram centrifugadas a $13.400 \mathrm{rpm}$, durante $30 \mathrm{~min}$. As alíquotas centrifugadas foram transferidas para vials para posterior análise de glicose em HPLC da mesma forma que foi realizada para a caracterização de carboidrato na biomassa.

\section{RESULTADOS E DISCUSSÕES}

\subsection{Caracterização da biomassa}

A caracterização da biomassa de três diferentes microalgas com potencialidade para produção em fotobiorreator ou em raceway ponds estão apresentadas na Tabela 1. Estas microalgas são conhecidas por sua potencialidade para produção de biocombustíveis (Enamala et al., 2018), ricas em lipídeos ou carboidratos.

Tabela 1. Teor de Carboidratos, Proteínas, Cinzas, Lipídeos e Amido na biomassa de microalgas.

\begin{tabular}{|c|c|c|c|}
\hline \multirow{2}{*}{ Parâmetros (\%) } & \multicolumn{3}{|c|}{ Microalgas } \\
\hline & Scenedesmus sp. & Spirulina (A. platensis) & Chlorella sp. \\
\hline Carboidratos totais & $16,31 \pm 1,94$ & $40,02 \pm 0,47$ & $8,08 \pm 0,35$ \\
\hline Amido & $12,09 \pm 0,03$ & $24,95 \pm 0,02$ & $2,31 \pm 0,01$ \\
\hline Proteínas & $35,37 \pm 1,15$ & $24,95 \pm 0,47$ & $26,41 \pm 0,24$ \\
\hline
\end{tabular}




\begin{tabular}{lccc} 
Cinzas & $5,91 \pm 0,15$ & $11,81 \pm 0,54$ & $35,81 \pm 4,34$ \\
Lipídeos & $12,07 \pm 1,13$ & $6,69 \pm 3,56$ & $14,41 \pm 19,72$ \\
\hline
\end{tabular}

Nenhuma das cepas analisadas apresentou alto teor de lipídeos. O teor de cinzas depende das condições de cultivo e separação. A Chlorella sp. apresentou alto teor de cinzas em função do método de secagem em estufa sem a centrifugação, utilizando apenas decantação, o que permite que nutrientes inorgânicos fiquem dissolvidos no meio em que está a biomassa. Amostras filtradas ou centrifugadas apresentam menor teor de cinzas.

Carboidratos podem representar a porção mais significativa da biomassa microalgal, e tem importância na aplicabilidade industrial da mesma. Para algumas espécies pode-se facilmente esperar até 50 \% do seu peso seco (Harun \& Danquah, 2011; Zhou et al., 2018). A microalga Spirulina foi a que apresentou a maior concentração de carboidratos e devido a isso foi então a escolhida para a otimização da hidrólise enzimática.

\subsection{HIDRÓLISE}

Para realização da hidrólise enzimática considerou-se que a amostra de biomassa da microalga Spirulina apresentou metade do teor de carboidratos em amido (24,95 \%) sendo promissor o uso de amilases na sua hidrólise. Para isso, foram testadas duas amilases em sequência da mesma forma que Schneider et al. (2018) utilizou para conversão do amido presente em arroz quebrado. A conversão em monossacarídeos com as amilases ( $\alpha$-amilase e glucoamilase) estão apresentadas na Tabela 2 .

Tabela 2. Conversão do amido em glicose da microalga Spirulina utilizando amilases.

\begin{tabular}{|c|c|c|c|}
\hline \multicolumn{2}{|c|}{ Concentração } & \multicolumn{2}{|c|}{ Glicose $(\%)$} \\
\hline & & Experimento 1 & Experimento 2 \\
\hline \multirow{2}{*}{ Amilases } & Liquozyme & $2,89 \pm 0,21$ & $6,78 \pm 0,11$ \\
\hline & Liquozyme + AMG & $19,75 \pm 0,69$ & $26,10 \pm 1,19$ \\
\hline
\end{tabular}

O teor de glicose com a utilização das duas amilases foi próximo ao valor de amido determinado previamente na biomassa, mostrando que o procedimento foi adequado para a primeira etapa do processo de conversão dos carboidratos. Após o uso das amilases seguiu-se a reação utilizando dois diferentes complexos de celulases, CTec2 e HTec2. Os resultados para concentração de glicose e xilose utilizando estes dois complexos estão apresentados na Tabela 3.

Os teores de monossacarídeos obtidos da biomassa estão de acordo com aquele encontrado na análise de carboidratos totais (40,02\%). Os valores obtidos na Tabela 3, representam o somatório dos açúcares obtidos na primeira etapa com amilases acrescido dos açúcares obtidos na segunda etapa com celulases, uma vez que os experimentos realizados com as celulases foram em sequência, após a primeira etapa com amilases.

Tabela 3. Resultados da hidrólise enzimática para enzima CTec2 e HTec2.

\begin{tabular}{|c|c|c|c|c|c|}
\hline $\begin{array}{l}\text { Concentração } \\
\text { Enzima (FPU) }\end{array}$ & & Glicose $(\%)$ & Xilose $(\%)$ & $\begin{array}{c}\text { Total } \\
(\%)\end{array}$ & $\begin{array}{c}\text { Rendimento } \\
(\%)\end{array}$ \\
\hline
\end{tabular}




\begin{tabular}{cccccc}
\hline & 2 & $28,72 \pm 2,27$ & $0,53 \pm 0,32$ & 29,25 & 73,1 \\
& 4 & $29,78 \pm 1,67$ & - & 29,78 & 74,4 \\
CTec2 & 6 & $29,47 \pm 0,67$ & $1,00 \pm 0,18$ & 30,47 & 76,1 \\
& 8 & $30,94 \pm 1,20$ & $0,36 \pm 0,48$ & 31,30 & 78,2 \\
& 12 & $37,87 \pm 0,27$ & $1,81 \pm 0,42$ & 39,68 & 99,2 \\
& 15 & $34,39 \pm 1,06$ & $1,17 \pm 0,44$ & 35,56 & 88,9 \\
& 30 & $35,39 \pm 1,01$ & - & 35,39 & 88,4 \\
& 40 & $35,55 \pm 1,35$ & $0,16 \pm 0,70$ & 35,71 & 89,2 \\
\hline HTec2 & 1,7 & 30,75 & 3,14 & 33,89 & 84,7 \\
& 3,5 & 34,59 & 6,09 & 40,68 & 101,6 \\
& 5,2 & 41,14 & - & 41,14 & 102,8 \\
& 6,9 & 41,52 & - & 41,52 & 103,7 \\
& 10,4 & 38,92 & 4,39 & 43,31 & 108,2 \\
& 13,8 & 32,66 & - & 32,66 & 81,6 \\
\hline
\end{tabular}

- não determinado

A conversão encontrada em ambos os casos se assemelham com o resultado do valor máximo de carboidratos contidos na biomassa, assegurando que a sequência de enzimas é adequada para este fim, liberando os monossacarídeos próximos a 100\% do conteúdo existente na biomassa. A Figura 2 apresenta o comportamento da produção de glicose com relação a concentração de celulases utilizadas nos experimentos. $\mathrm{O}$ valor inicial, relativo à adição de amilases corresponde ao ponto zero de adição de celulase e, portanto, é possível identificar que a concentração de celulases escolhida para a conversão foi de 12 FPU com a enzima CTec2 e de 6,9 FPU com a enzima HTec2.

Outros autores também encontraram condições otimizadas para a sacarificação de biomassa de microalgas. Um estudo realizado com a cepa Chlorococum humicola por Harun and Danquah (2011), identificou condições otimizadas para realizar a hidrolise enzimática com celulase para microalga como $48{ }^{\circ} \mathrm{C}$ de temperatura ideal com pH de 5,5 para produzir a maior conversão de polissacarídeos em glicose. O trabalho realizado por Fu et al. (2010) com celulases imobilizadas atingiu aproximadamente $70 \%$ de conversão em reações a $50{ }^{\circ} \mathrm{C}$ durante $72 \mathrm{~h}$ utilizando a cepa de Chlorella sp. Ometto et al. (2014) realizou um estudo com a cepa Arthrospira máxima (Spirulina) e outras cepas, como Scenedesmus obliquus e Chlorella sorokiniana no qual identificou que a hidrolise enzimática é o melhor método em termos de consumo de energia se comparada com outros métodos

(ultrassonicação e térmico) para hidrolisar carboidratos.

Figura 2. A) Experimentos de hidrólise em sequência de enzimas com amilases e celulase CTec2; 


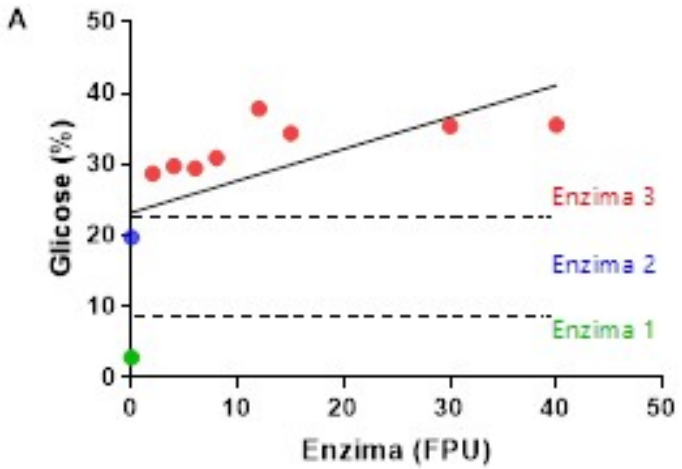

B) Experimentos de hidrólise em sequência de enzimas com amilases e celulase HTec2.

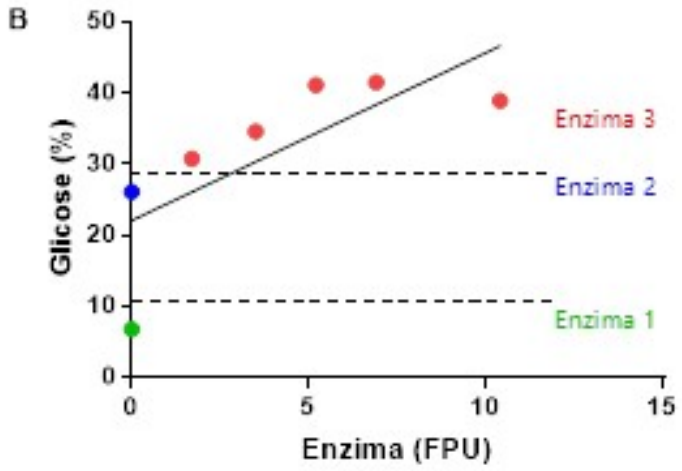

\section{CONCLUSÃO}

A partir da biomassa de microalga, utilizando especificamente a biomassa de Spirulina, contendo 40,02\% de carboidratos, foi possível fazer a hidrólise empregando uma sequência de enzimas, $\square$-amilase, glucoamilase e celulases. A conversão dos polissacarídeos foi total considerando a presença de amido e outros polissacarídeos, como a celulose contida na parede celular.

Destaca-se também que os resultados encontrados colaboram para viabilizar o uso da biomassa de microalgas para o desenvolvimento de outros produtos como etanol, biopolímero, ácido lático e outras moléculas com alta representatividade nos produtos que a sociedade consome no dia-dia, tornando a produção mais renovável.

\section{AGRADECIMENTOS}

Ao CNPq e a Fapergs, pelas bolsas IC, à Coordenação de Aperfeiçoamento de Pessoal de Nível Superior Brasil (CAPES) - Código 001; Conselho Nacional de Pesquisa (CNPq) - Protocolo 306178/2012-5 e ao Ministério de Ciência, Tecnologia e Inovação (MCTI) - Número 01.0144.00/2010.

\section{REFERÊNCIAS}

Abomohra, A.E.-F., Jin, W., Tu, R., Han, S.-F., Eid, M., Eladel, H. 2016. Microalgal biomass production as a sustainablefeedstock for biodiesel: Current status and perspectives. Renewable and Sustainable Energy Reviews, 64, 596-606.

Adney, B., Baker, J. 2008. Maeasurement of cellulase activities.

Al Abdallah, Q., Nixon, B.T., Fortwendel, J.R. 2016. The Enzymatic Conversion of Major Algal and Cyanobacterial Carbohydrates to Bioethanol. Frontiers in Energy Research, 4, 36. 
Bligh, E.G., Dyer, W.J. 1959. A rapid method of total lipid extraction and purification. Can J Biochem Physiol, 37(8), 911-7.

Chen, W.-H., Chu, Y.-S., Liu, J.-L., Chang, J.-S. 2018. Thermal degradation of carbohydrates, proteins and lipids in microalgae analyzed by evolutionary computation. Energy Conversion and Management, 160, 209-219.

Demirbas, M.F. 2011. Biofuels from algae for sustainable development. Applied Energy, 88(10), 3473-3480.

Dowe, N., McMillan, J. 2008. SSF Experimental Protocols - Lignocellulosic Biomass Hydrolysis and Fermentation. National Renewable Energy Laboratory.

Enamala, M.K., Enamala, S., Chavali, M., Donepudi, J., Yadavalli, R., Kolapalli, B., Aradhyula, T.V., Velpuri, J., Kuppam, C. 2018. Production of biofuels from microalgae - A review on cultivation, harvesting, lipid extraction, and numerous applications of microalgae. Renewable and Sustainable Energy Reviews, 94, 49-68.

Fernandes, B., Dragone, G., Abreu, A., Geada, P., Teixeira, J., Vicente, A. 2011. Starch determination in Chlorella vulgaris—a comparison between acid and enzymatic methods.

Fu, C.-C., Hung, T.-C., Chen, J.-Y., Su, C.-H., Wu, W.-T. 2010. Hydrolysis of microalgae cell walls for production of reducing sugar and lipid extraction. Bioresource Technology, 101(22), 8750-8754.

Harun, R., Danquah, M.K. 2011. Enzymatic hydrolysis of microalgal biomass for bioethanol production. Chemical Engineering Journal, 168(3), 1079-1084.

Hernández, D., Riaño, B., Coca, M., García-González, M.C. 2015. Saccharification of carbohydrates in microalgal biomass by physical, chemical and enzymatic pre-treatments as a previous step for bioethanol production. Chemical Engineering Journal, $262,939-945$

Mata, T.M., Martins, A.A., Caetano, N.S. 2010. Microalgae for biodiesel production and other applications: A review. Renewable and Sustainable Energy Reviews, 14(1), 217-232.

Moreno-Garcia, L., Adjallé, K., Barnabé, S., Raghavan, G.S.V. 2017. Microalgae biomass production for a biorefinery system: Recent advances and the way towards sustainability. Renewable and Sustainable Energy Reviews, 76, 493506.

Ometto, F., Quiroga, G., Pšenička, P., Whitton, R., Jefferson, B., Villa, R. 2014. Impacts of microalgae pre-treatments for improved anaerobic digestion: Thermal treatment, thermal hydrolysis, ultrasound and enzymatic hydrolysis. Water Research, 65 , 350-361.

Raheem, A., Prinsen, P., Vuppaladadiyam, A.K., Zhao, M., Luque, R. 2018. A review on sustainable microalgae based biofuel and bioenergy production: Recent developments. Journal of Cleaner Production, 181, 42-59.

Rempel, A., Machado, T., Treichel, H., Colla, E., Margarites, A.C., Colla, L.M. 2018. Saccharification of Spirulina platensis biomass using free and immobilized amylolytic enzymes. Bioresource Technology, 263, 163-171.

Schneider, R.d.C.d.S., Junior, C.S., Fornasier, F., de Souza, D., Corbellini, V.A. 2018. Bioethanol production from broken rice grains. Interciencia, 43(12), 846-851.

Sivaramakrishnan, R., Incharoensakdi, A. 2018. Utilization of microalgae feedstock for concomitant production of bioethanol and biodiesel. Fuel, 217, 458-466.

Sluiter, A., Hames, B., Ruiz, R., Scarlata, C., Sluiter, J., Templeton, D., Crocker, D. 2008. Determination of Structural Carbohydrates and Lignin in Biomass-NREL/TP-510-42618.

Templeton, D.W., Laurens, L.M. 2015. Nitrogen-to-protein conversion factors revisited for applications of microalgal biomass conversion to food, feed and fuel. Algal Research, 11, 359-367.

Vo, H.-N.-P., Bui, X.-T., Nguyen, T.-T., Nguyen, D.D., Dao, T.-S., Cao, N.-D.-T., Vo, T.-K.-Q. 2018. Effects of nutrient ratios and carbon dioxide bio-sequestration on biomass growth of Chlorella sp. in bubble column photobioreactor. Journal of Environmental Management, 219, 1-8.

Zhou, T., Wang, J., Zheng, H., Wu, X., Wang, Y., Liu, M., Xiang, S., Cao, L., Ruan, R., Liu, Y. 2018. Characterization of additional zinc ions on the growth, biochemical composition and photosynthetic performance from Spirulina platensis. Bioresource Technology, 269, 285-291. 